\title{
Influences of Recycled Concrete Aggregate and Flyash on Properties of GRC
}

\author{
CHENG HaiLi ${ }^{1, a *}$ LIU GuoQiang ${ }^{1, b}$ YANG FeiHua ${ }^{2, c}$ \\ ${ }^{1}$ North China University of Technology, Beijing, 100144, \\ ${ }^{2}$ State Key Laboratory of Solid Waste Reuse For Building Materials, Beijing 100041 \\ atkggig@sina.com \\ b1280381899@qq.com \\ cchyangfeihua@126.com
}

Keywords: waste concrete, GRC, durability

\begin{abstract}
Using the method of accelerating GRC ageing, the effects of waste concrete and fly ash on flexural Strength and durability of GRC were researched. The results show that the durability of GRC can be improved to some extent when $30 \%$ of natural sand in GRC was replaced by waste concrete, but the improvement on the durability of GRC was limited when $20 \%$ of cement was replaced by flyash. The improving effect on the durability of GRC with $30 \%$ of natural sand replaced by waste concrete, is greater than the one with $20 \%$ ordinary portland cement replaced by fly ash, and the effect is greater when natural sand and cement are replaced simultaneously by waste concrete and fly ash with the replacement rate mentioned above.
\end{abstract}

\section{Introduction}

Glass fiber Reinforced Cement (GRC) products are applied broadly to many fields including architecture, civil engineering, agriculture livestock and fishery, environmental art and military engineering, especially to fields of architecture and civil engineering for the advantages such as light in weight, crack resistance, shock-resistance, thermal insulation, water-proof and fire-proof. However, the limitation for the more wide application could be attributed mainly to the decrease of durability. Besides, I like to think that as far as sustainable development is concerned, GRC products are facing another problem: an awful lot of natural sand resources were consumed during the production and application of GRC (in GRC, the cement-sand ratio is either $1: 1$ or $1: 2$, meaning natural sand consists of at least 50\%). With the development of gross national economy, natural sand resources are consumed in many industries, which will be an important obstacle to the wide application of GRC products.

Aiming at the problem of durability of GRC, the current solutions are mainly: (1) Using 'double insurance' technologies such as low-alkalinity sulphoaluminium cement and alkali-resisting fiber glass, but due to the problems of low-alkalinity sulphoaluminium cement including high in price, low in productivity and strength decreasing [1-2], its application is also limited. (2) Adding mineral admixture such as fly ash, silica fume into GRC based on Ordinary Portland Cement (OPC), so as to improve its durability. There are currently no research documents on the problem of consuming natural sand resources by GRC. There are also no research documents on improving the durability of GRC from the perspective of aggregate.

On the other hand, with the speeding up of China's urbanization process, due to urban construction and large scale redevelopment, as well as the scale construction of residence community and implement of road modification and extension projects, the discharge of construction waste produced has risen sharply. According to statistics, the emissions of construction 
waste in China had reached 1.4 billion tons in 2013, three times larger compared to 2009 [3], among them, Waste Concrete(WC) accounted for about 41\% [4], meaning that 574 million tons of WC was discharged in China in 2013, but the reutilization rate of WC is very low.

In this way, on the basis of previous research [5], parts of natural sand and OPC were replaced with WC and fly ash respectively, the influence of the two, either combined or separated, on the properties of GRC was researched.

Tab.1 Main properties of $\mathrm{P} \cdot \mathrm{O} 42.5$

\begin{tabular}{cccccc}
\hline Setting time[min] & & \multicolumn{2}{c}{ Compressive strength[Mpa] } & \multicolumn{2}{c}{ Flexural strength[Mpa] } \\
\hline initial & F20inal & $3 \mathrm{~d}$ & $28 \mathrm{~d}$ & $3 \mathrm{~d}$ & $28 \mathrm{~d}$ \\
105 & 185 & 22.0 & 45.1 & 5.1 & 8.5 \\
\hline
\end{tabular}

Table 2 Physical properties of the natural sand and RWCA

\begin{tabular}{cccccc}
\hline Physical property & $\begin{array}{c}\text { Bulk } \\
\text { density }\left[\mathrm{g} / \mathrm{cm}^{3}\right]\end{array}$ & $\begin{array}{c}\text { Moisture } \\
\text { content[\%] }\end{array}$ & $\begin{array}{c}\text { Range of particle size } \\
{[\mathrm{mm}]}\end{array}$ & $\begin{array}{c}\text { Fineness } \\
\text { modulus }\end{array}$ & $\begin{array}{c}\text { Grain } \\
\text { grading }\end{array}$ \\
\hline natural sand & 1.70 & 0.35 & $0.15-4.75$ & 2.22 & Well graded \\
Waste concrete & 1.41 & 0.86 & $0.15-4.75$ & 2.7 & Well graded \\
\hline
\end{tabular}

Table 3 Chemical composition of waste concrete [\%]

\begin{tabular}{cccccccccccccc}
\hline $\mathrm{SiO}_{2}$ & $\mathrm{Al}_{2} \mathrm{O}_{3}$ & $\mathrm{Fe}_{2} \mathrm{O}_{3}$ & $\mathrm{FeO}$ & $\mathrm{MgO}$ & $\mathrm{CaO}$ & $\mathrm{Na}_{2} \mathrm{O}$ & $\mathrm{K}_{2} \mathrm{O}$ & $\mathrm{H}_{2} \mathrm{O}^{-}$ & $\mathrm{TiO}_{2}$ & $\mathrm{P}_{2} \mathrm{O}_{5}$ & $\mathrm{MnO}$ & LOI & Total \\
\hline 49.05 & 8.81 & 2.06 & 0.91 & 4.57 & 15.14 & 1.7 & 1.62 & 0.86 & 0.38 & 0.093 & 0.22 & 15.15 & 99.7 \\
\hline
\end{tabular}

Tablb 4 Main properties of alkali-resistant glass fibre

\begin{tabular}{ccccccc}
\hline $\begin{array}{c}\text { Linear } \\
\text { density[tex }]\end{array}$ & $\begin{array}{c}\text { Length } \\
{[\mathrm{mm}]}\end{array}$ & $\begin{array}{c}\text { Breaking trength } \\
{[\mathrm{N} / \text { tex }]}\end{array}$ & $\begin{array}{c}\text { Moisture } \\
\text { content[\%] }\end{array}$ & $\begin{array}{c}\text { combustible matter } \\
\text { content[\%] }\end{array}$ & $\begin{array}{c}\mathrm{ZrO}_{2} \\
{[\%]}\end{array}$ & $\begin{array}{c}\left(\mathrm{ZrO}_{2}+\mathrm{TiO}_{2}\right) \\
{[\%]}\end{array}$ \\
\hline 3109 & 12 & 0.34 & 0.15 & 1.6 & 14.9 & 19.5 \\
\hline
\end{tabular}

\section{Major raw materials and properties}

Cement The main properties of OPC with a strength grade of 42.5 are in table 1 .

Natural sand The main properties of natrual sand are in table 2.

Recycled Waste Concrete Aggregate

Coming from demolished old buildings, Recycled Waste Concrete Aggregate (RWCA) was produced after being cracked and screened, its main physical properties are in table 2, and chemical components in table 3 .

Fly ash Grade II

Fasciculus shortcut alkali-resisting glass fiber

The properties of alkali-resisting glass fiber are listed in table 4 .

Water reducer The water reducer belongs to polycarboxylate-type.

\section{Experime ntal process}

\section{Making specime ns}

Add OPC, aggregate, admixture, additive and shortcut glass fiber with a certain proportion into cement mortar pot, add some part of water at first and quickly stir the mixture, so as the glass fiber could be fully dispersed, the rest of water was then all poured into the pot and mixed again. The mix proportion are listed in table 5. (cement-aggregate ratio at 1:1.96, water-binding materials ratio at 
$0.48,30 \%$ of natural sand was replaced with RWCA, $20 \%$ of OPC was replaced with fly ash, the amount of water reducer was adjusted according to the principle that the flowability of different mix of GRC was similar during the experiment). The specimens were made in $40 \mathrm{~mm} \times 40 \mathrm{~mm} \times 160 \mathrm{~mm}$ mould, and dismantled after cured for $1 \mathrm{~d}$ under normal condition (temperature: $15^{\circ} \mathrm{C} \sim 20^{\circ} \mathrm{C}$, relative moisture between $60 \%$ to $70 \%$ ), then the specimens were cured in different conditions for different periods. The results are in table 6 .

\section{Mechanical property test}

The mechanical property test was carried out according to GB/T17671-1999 'Test method for strength of hydraulic cement mortar '(ISO).

\section{Research method of GRC durability}

According to Litherland[6], the long term durability could be predicted with the method of accelerating aging. Since glass fiber mainly plays a role in improving the bending strength, preventing cracking and enhancing the toughness of the cement matrix, the degree of its erosion in cement matrix is mainly reflected in the change of bending property of cement matrix. Thus, the flexural strength of GRC specimens which had been cured for $1 \mathrm{~d}$ under natural condition was tested after being cured for $7 \mathrm{~d}, 28 \mathrm{~d}$ and $56 \mathrm{~d}$ respectively in normal temperature $\left(15-20^{\circ} \mathrm{C}\right)$ water and $50^{\circ} \mathrm{C}$ one. Through calculating the Retention of Flexural Strength(RFS) of GRC in different aging period, the durability of GRC was researched. RFS is calculated with formula (1), and the experiment and calculation results are listed in table 6 .

$$
\text { RFS }(\%)=\frac{\text { Flexural strength value of specimens cured in } 50^{\circ} \mathrm{C} \text { water }(\mathrm{MPa})}{\text { Flexural strength value of specimens cured in normal temperature water }(\mathrm{MPa})} \times 100 \%
$$

Table 5 Mix of GRC with waste concrete aggregate

\begin{tabular}{lcc|ccccc}
\hline \multicolumn{1}{c|}{ No. } & Cement $[\mathrm{g}]$ & Flyash[g] & Sand $[\mathrm{g}]$ & RWCA $[\mathrm{g}]$ & Water[ml] & Glass fibre $[\mathrm{g}]$ & $\begin{array}{c}\text { Water } \\
\text { reducer }[\mathrm{g}]\end{array}$ \\
\hline $\mathrm{N}$ & 569 & 0 & 1116 & 0 & 275 & 29.3 & 0.0 \\
R30 & 569 & 0 & 790 & 326 & 275 & 29.3 & 1.0 \\
F20N & 455 & 114 & 1116 & 0 & 275 & 29.3 & 0.5 \\
F20R30 & 455 & 114 & 790 & 326 & 275 & 29.3 & 1.0 \\
\hline
\end{tabular}

Table 6 The properties of GRC with waste concrete aggregate and flyash

\begin{tabular}{|c|c|c|c|c|c|c|c|c|c|}
\hline \multirow{3}{*}{ No. } & \multicolumn{6}{|c|}{ Flexural strength [Mpa] } & \multirow{2}{*}{\multicolumn{3}{|c|}{ RFS[\%] }} \\
\hline & \multicolumn{3}{|c|}{ Cured in normal temperature water } & \multicolumn{3}{|c|}{ Cured in $50^{\circ} \mathrm{C}$ wate } & & & \\
\hline & $7 \mathrm{~d}$ & $28 \mathrm{~d}$ & $56 \mathrm{~d}$ & $7 \mathrm{~d}$ & $28 \mathrm{~d}$ & $56 \mathrm{~d}$ & $7 \mathrm{~d}$ & $28 \mathrm{~d}$ & $56 \mathrm{~d}$ \\
\hline $\mathrm{N}$ & 6.9 & 9.3 & 9.8 & 8.4 & 8.5 & 8.7 & 122 & 91 & 89 \\
\hline R30 & 6.4 & 9.0 & 9.5 & 9.7 & 9.8 & 10.6 & 152 & 109 & 112 \\
\hline F20N & 5.3 & 8.7 & 9.2 & 8.3 & 8.4 & 8.6 & 157 & 96 & 93 \\
\hline F20R30 & 5.9 & 7.6 & 9.5 & 9.7 & 10 & 10.7 & 164 & 131 & 113 \\
\hline
\end{tabular}

\section{Analysis on experime ntal data}

\section{Influence factors analysis on flexural strength of GRC}

Comparing R30 and $\mathrm{N}$ from Table 6 and Fig. 1, it can be seen that when cured in normal temperature water, the flexural strength of GRC, which $30 \%$ of natural sand being replaced by waste concrete, decreased slightly in the three curing periods. This is relevant to the character of 
RWCA that its strength is lower than natural sand.

Comparing F20N and $\mathrm{N}$, it can be seen that when cured in normal temperature water, the flexural strength GRC, which $20 \%$ of cement being replaced by flyash, decreased in the three different curing periods, and all lower than R30. The strength dropped sharply in 7d, since the reduction of the amount of cement, especially in early age, the pozzolanic activity of fly ash did not take effect yet, thus the strength dropped sharply in $7 \mathrm{~d}$, but in later age, the pozzolanic activity of flyash began to take effect, thus the drop of strength decreased.

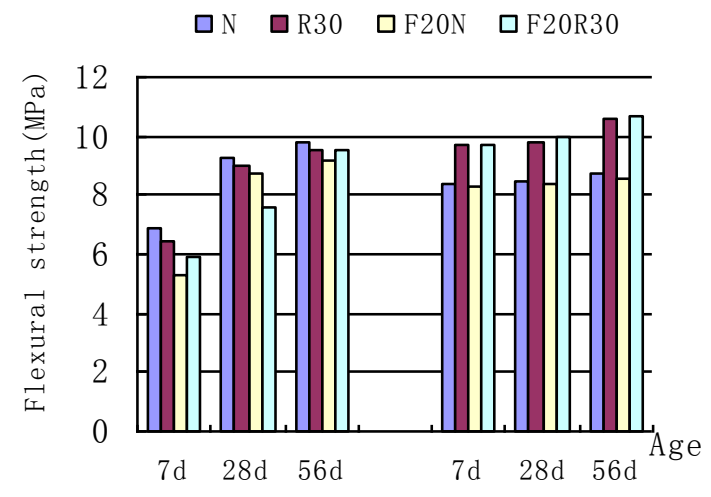

Fig. 1 The relationship between flexural strength and mix proportion of GRC cured in normal temperature and $50^{\circ} \mathrm{C}$ water respectively

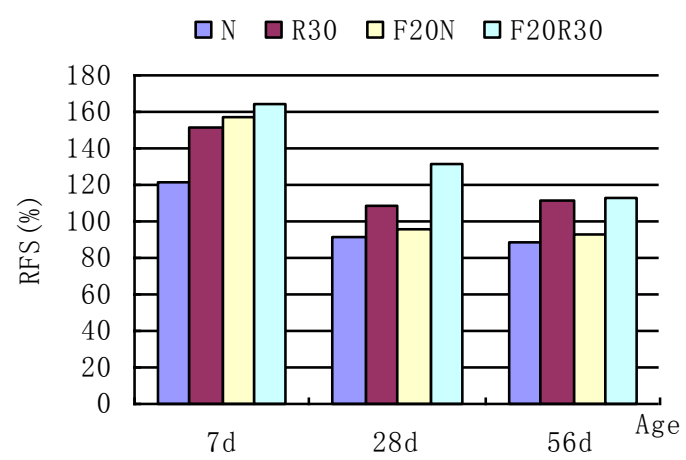

Fig.2 The relationship between retention of flexural strength and mix proportion of GRC

The situation of F20R30 cured in normal temperature water was similar to R30 and F20N, due to the joint effect brought by two elements - the low strength of RWCA and the decrease of cement amount-the flexural strength of GRC decreased greatly in $7 \mathrm{~d}$ and $28 \mathrm{~d}$, but the falling range of strength decreased gradually in 56d after the pozzolanic activity of fly ash took effect.

\section{Influence factors analysis on durability of GRC}

As can be seen from table 6 and Fig. 2, the RFS of GRC with four different mix proportions all decreased with the growth of curing age, regardless of whether WC or fly ash was added. (apart from R30 in 56d, which probably due to data fluctuation ) That means the aging of fiber glass being accelerated after cured in $50^{\circ} \mathrm{C}$ water, thus the flexural strength decreased due to the damage of fiber glass. However, the decrease extent of RFS varied due to different mix proportions. In the four mix proportions, the strength in $7 \mathrm{~d}$ cured in $50^{\circ} \mathrm{C}$ water all increased, since heating could accelerate the hydration reaction of cement, and the time in $7 \mathrm{~d}$ is not enough for fiber glass to be eroded, but the difference occurred among the changes of strength in four different mix proportions with the growth of curing age.

\section{Influence of RWCA on durability of GRC}

Comparing the R30 and $\mathrm{N}$ from table 6 and Fig. 2, it can be seen that after cured in $50{ }^{\circ} \mathrm{C}$ water, apart from in $7 \mathrm{~d}$, the strength of $\mathrm{N}$ in $28 \mathrm{~d}$ and $56 \mathrm{~d}$ both decreased compared to the amount cured in normal temperature water, so the RFS was over $100 \%$ in $7 \mathrm{~d}$, but in $28 \mathrm{~d}$ and $56 \mathrm{~d}$, both were less than $100 \%$. The reason was known to all: in early age, OPC has not been fully hydrated, thus there is insufficient $\mathrm{Ca}(\mathrm{OH})_{2}$ produced from the OPC hydration, and in a shorter period of time, thus the extent of erosion of fiber glass was not enough, but increasing temperature is good for cement to be fully hydrated and hardened, in this way, the strength was higher after cured in $50{ }^{\circ} \mathrm{C}$ water than in normal temperature water, and the RFS were higher than $100 \%$. But with the growth of curing age, more and more $\mathrm{Ca}(\mathrm{OH})_{2}$ was produced by full hydration of cement, and fiber glass was eroded due 
to being exposed in an alkali environment full of $\mathrm{Ca}(\mathrm{OH})_{2}$ for a long time, thus, the RFS were less than $100 \%$.

But for GRC with $30 \%$ of natural sand replaced by RWCA (R30), cured under $50^{\circ} \mathrm{C}$ water, the flexural strength were increased in different extent in the three different ages, as such, the RFS in the three ages were all above 100\%, though the RFS lowered with the growth of curing time, namely, the decrease of strength could slow down just for $30 \%$ of natural sand was replaced by RWCA. It can be speculated that RWCA could 'protect' or 'prevent' fiber glass from being eroded. This might probably because the surface of RWCA is rough, porous and has relatively strong absorption of water, it could absorb the redundant water in fresh cement mortar mixture, thus could both decrease the actual water-cement ratio on the surface of aggregate and the effective water-cement ratio of fresh GRC material, so as to make the fiber-cement interface more dense, and weaken the trend of the enrichment and the production of large particle crystals of $\mathrm{Ca}(\mathrm{OH})_{2}$, thus weaken the erosion effect on fiber glass. All those still requires confirmation via methods of analysis with equipments.

\section{Influence of fly ash on durability of GRC}

Comparing F20N and N, R30F20 and R30 from Table 6 and Fig. 2, it can be seen that, the RFS was higher after adding fly ash, that was because when part of OPC was replaced by fly ash, the amount of $\mathrm{Ca}(\mathrm{OH})_{2}$ produced from cement hydration decreased, and meanwhile, fly ash could react with $\mathrm{Ca}(\mathrm{OH})_{2}$, thus parts of $\mathrm{Ca}(\mathrm{OH})_{2}$ could be consumed, so that the fiber glass could be eroded lesser. Comparing the RFS of R20 and R30F20, it can be seen that the 'protection effect' of fly ash on fiber glass in RWCA-GRC system was stronger than in natural aggregate-GRC system, which was the result from the joint effect by both RWCA and fly ash.

\section{Influence of combination of RWCA and fly ash on durability of GRC}

As can be seen from Table 6 and Fig. 2, R30F20、F20N、R30, compared to N, the RFS of R30F20 in three curing periods was the highest, meaning the effect of combination of RWCA and fly ash, which the replacement to natural sand and cement was $30 \%$ and $20 \%$ respectively, was good for the durability of GRC, and better than the one when the two are added separately. That was the joint result from both the porous, absorption character of RWCA and pozzolanic activity of fly ash.

\section{Conclusion and discussion}

\section{Conclusions}

1)The flexural strength and durability of GRC could be increased, when natural sand was replaced by RCWA.

2) The improvement on durability of GRC when $20 \%$ of cement was replaced by fly ash is limited.

3) When $30 \%$ of natural sand was replaced with RWCA, the improvement on durability of GRC is better than when $20 \%$ of cement was replaced with fly ash.

4)The effect of combination of RWCA and fly ash, which the replacement to natural sand and cement is $30 \%$ and $20 \%$ respectively, is good for the durability of GRC, and better than the one when the two are added separately.

\section{Discussions}

1) The research on using RWCA as aggregate for GRC is not commonly seen, thus the research should be carried out more specifically. Only preliminary experimental work has been done in this article.

2) RWCA possess some properties of light weight aggregate such as low strength and high 
water-absorbent, thus, adding RWCA into GRC will affect the workability in different extent. As such, suitable species of water reducer is needed. The conclusion in this article comes up with only the water reducer used in this experiment.

3) The cement used is based on ordinary cement with high-alkali binding material, which could be used as reference for GRC in 'double-insurance' system.

4) The influence mechanism of RWCA on durability of GRC still requires deeper research via equipment analysis, which is the writer will focus on in the future.

\section{Acknowledge ments}

The authors are grateful to BEIJING NATURAL SCIENCE FOUNDATION for supporting this study through Project 'Study of Waste Concrete Effect on Durability of GRC and It's Mechanism' (No.2013214), they also thank STATE KEY LABORATORY OF SOLID WASTE REUSE FOR BUILDING MATERIALS for supporting this study through Project 'Application Technology Research on Producing Recycled Aggregate GRC With Construction Waste’ （No. SWR-2012-003）

\section{References}

[1] $\mathrm{Fu}$ xinghua, Hou wenping, et al. An investigation in the properties improvement of sulphoaluminate cement[J] Cement technology (in Chinese). 2001.2: 10-15

[2] Hou Wenping,Fu Xinghua,Huang Shifeng,Lu Xiaoping,Meng Xianchun. Influence of additives on the properties of sulphoaiuminate cement system[J]. Journal of Jinan University(Sci.\&Tech.) (in Chinese) ,2002.16(1):6-8.

[3] Chen Jialong. The present situation and suggestions of construction and demolition waste resourcezation in China[J]. construction technology(in Chiinese), 2014, (1): 9-12

[4] Li hui, Su Yuanting, Zhang Hao. Basic properties of construction waste from Xi'an[J]. Bulletin of the ChineseCeramic Society(in Chiinese), 2015,34(3): 853-858

[5] Cheng haili, Yang feihua, Wang baogen. Research on recycling use of waste brick in GRC[J] Recyclable Resources and Circular Economy(in Chinese), 2014, (08): 23-26

[6] Litherland K.L, Oakley DR, Proctor BA. The use of accelerated ageing procedures to predict the long term strength of GRC composites. Cement and Concrete Research. 1981, (11): 455-466 